\title{
THOUGHTS AND AWARENESS OF MEDICAL STUDENTS ABOUT THE COVID-19 PANDEMIC
}

Hilal Sena Çifcibaşı ${ }^{1}$, Alperen Elibol ${ }^{2}$, Berkay Kef ${ }^{3}$, Bengisu Gür, Selin Kolsuz ${ }^{5}$, Berra Kurtoğlu ${ }^{6}$, Hasan Orkun İpsalalı ${ }^{7}$, Nazlıcan Kükürtcü̈ ${ }^{8}$, Ece Şenyiğit ${ }^{1}$, Ekin Altınbaş ${ }^{2}$, Berfin Tan ${ }^{1}$, Aslı Göztepe ${ }^{1}$, Alperen Taha Certel ${ }^{1}$, Arda Ulaş Mutlu ${ }^{1}$, Burak Bardakçı ${ }^{1}$, Elif Cengiz ${ }^{1}$, Nigar Keleş Çelik ${ }^{9}$, Can Erzik ${ }^{10}$, Mehmet Ziya Doymaz ${ }^{11}$, Serkan Atıcı ${ }^{12}$, Melike Şahiner ${ }^{13}$, Selis Gülseven Güven ${ }^{14}$

${ }^{1}$ Trakya University School of Medicine, Edirne, TURKEY

${ }^{2}$ Acıbadem Mehmet Ali Aydınlar University School of Medicine, Istanbul, TURKEY

${ }^{3}$ Okan University School of Medicine, Istanbul, TURKEY

${ }^{4}$ Bezmialem Vakif University School of Medicine, Istanbul, TURKEY

${ }^{5}$ Koç University School of Medicine, Istanbul, TURKEY

${ }^{6}$ TOBB University of Economics and Technology School of Medicine, Ankara, TURKEY

${ }^{7}$ Marmara University School of Medicine, Istanbul, TURKEY

${ }^{8}$ Akdeniz University School of Medicine, Antalya, TURKEY

${ }^{9}$ Department of Anatomy, Akdeniz University School of Medicine, Antalya, TURKEY

${ }^{10}$ Department of Medical Biology, Marmara University School of Medicine, Istanbul, TURKEY

${ }^{11}$ Department of Medical Microbiology, Bezmialem Vakif University School of Medicine, Istanbul, TURKEY

${ }^{12}$ Division of Pediatric Infectious Diseases, Department of Pediatrics, Okan University School of Medicine, Istanbul, TURKEY

${ }^{13}$ Department of Medical Education/Physiology, Acıbadem Mehmet Ali Aydınlar University School of Medicine, Istanbul, TURKEY

${ }^{14}$ Department of Ear-Nose and Throat Surgery, Trakya University School of Medicine, Edirne, TURKEY

\section{ABSTRACT}

Aims: This study aims to evaluate medical students' knowledge, thoughts, and awareness of the COVID-19 pandemic. Methods: A questionnaire consisting of 31 questions was prepared for this descriptive study. In the questionnaire, medical students' knowledge, attitudes and behaviors during the COVID-19 pandemic were investigated. Categorical variables are demonstrated as numbers and percentages, whereas continuous variables are presented as minimum, maximum, and mean values. Results: A total of 575 participants completed the questionnaire. The mean participant age was 21.7 years. Fifty-two percent of participants knew about the coronaviridae family before the outbreak and 38.8\% were informed about COVID-19 in their medical schools. Of the students, $99.7 \%$ stated that the first case's origin was in China. Eighty percent of the participants stated that droplet spread is the transmission route of COVID-19. The most common opinion about the incubation period of the SARS CoV-2 was two to twelve days. Being older than 65 years old, having a comorbidity, being immunosuppressed, or working in the healthcare sector were the most particular risk factors to get infected. The majority of the participants follow the vaccine developments from social media, radio and television. According to $75.83 \%$ of the participants, all people should wear a mask in daily life for protection. Conclusion: The epidemiology and diagnostic factors of COVID-19 are well known by medical students. To minimize information pollution and raise awareness, medical students should be educated about pandemic and management of it. Further evaluation with various methods and more participants may help to better understand the awareness of the COVID-19 pandemic in medical students. Keywords: COVID-19, SARS CoV-2, medical student, pandemic

Address for Correspondence: Hilal Sena Çiftcibaşı, Trakya University School of Medicine, Edirne, TURKEY e-mail: hilalsena98@gmail.com ORCID: orcid.org/0000-0002-9507-1092

Received: 03.06.2020 Accepted: 15.06.2020 • DOI: 10.4274/tmsj.galenos.2020.07.02.01 Available at: tmsj.trakya.edu.tr

Cite this article as: Ciftcibaş $\mathrm{HS}$, Elibol A, Kef B et al. Thoughts and awareness of medical students about the COVID-19 pandemic. Turkish Med Stud J 2020;7(2):44-64. 


\section{INTRODUCTION}

Ever since the Severe Acute Respiratory Syndrome (SARS) outbreak in 2002, a large number of SARS related coronaviruses (SARS-CoV) have been discovered (1). In December 2019, pneumonia with an unknown etiology was detected in China (2). On January 3rd, 2020, 44 patients with pneumonia of unknown etiology have been reported to the World Health Organization (WHO) by the national authorities in China (2). The following researches detected that it was a new type of SARS CoV-2. The origin of Coronavirus Disease-19 (COVID-19) was traced back to an animal market in Wuhan, China (1). On 30 January 2020, COVID-19 has been declared as the sixth public health emergency of international concern by the WHO (3). According to the WHO's official website, more than 3 million SARS CoV-2 cases and 243 thousand of deaths by SARS CoV-2 have been reported around the globe (as of 6 May 2020). Epidemiologic and retrospective researches found that people older than the age of 65 and people who are either immunosuppressed, pregnant, or chronically ill are at a greater risk of morbidity and mortality than other groups (4).

The virus encodes 4 different proteins that allow it to attach to the surface of the human cells and enter the cell via the human angiotensin-converting enzyme, whereafter the interaction starts a cytokine storm to bring out the symptoms (5). The main symptoms that patients contracted with COVID-19 are dry cough, fever, and tiredness. Other symptoms include shortness of breath, sputum production, myalgia, sore throat, and headache (6). Centers for Disease Control and Prevention (CDC) announced that some symptoms of COVID-19 require immediate medical attention (7). The patients having difficulty in breathing, persistent pain in the chest, bluish lips, or inability to arouse are encouraged to seek urgent medical intervention. Most of the time, symptoms do not appear in the first 2 days of exposure. The incubation period of COVID-19 is estimated to be between 2-14 days. However, an article published in JAMA reported a case with an incubation period of 19 days (8).

Coronaviruses can spread through ingestion or inhalation of respiratory droplets that are released to the environment by coughing or sneezing, or through contact with infected surfaces (9).

Currently, there are different diagnostic methods used in COVID-19: most prominent methods are reverse transcription-polymerase chain reaction (RT-PCR) and computed tomography (CT) scans (10). Although some studies suggest that oropharyngeal swabs can also be used in sample collection (11), the CDC recommends the usage of nasopharyngeal swabs (12). The collected samples are stored in $2-8^{\circ} \mathrm{C}$ for up to 72 hours before they are sent to be analyzed further. CT scans are not directly used as a diagnostic tool because of the high rate of misdiagnosis. Patients are diagnosed with ground glass opacities, interlobular septal thickening, and air bronchogram signs. A study by Li et al (13). reported that $88 \%$ of 919 patients had multiple lesions in both of the lungs with ground-glass opacities. Overall, the new coronavirus disease is usually diagnosed by RT-PCR and CT scans (14).

The virus can be isolated from many animals, but bats are accepted as the major natural coronavirus reservoir (15). Several studies found that animals, especially domestic animals (including pets) can be infected with the virus (15).

Medical staff has always been at risk of infective diseases because of the fact that they are in close contact with patients. As we know, COVID-19 can also transmitted from asymptomatic patients and this is multiplying the risk of getting infected (16). One patient in Wuhan who would undergo surgery had infected 14 health care workers which 12 of them was in close contact (17). These kinds of events and cases and the fact that we do not know much about COVID-19 are making the situation riskier and more stressful. We should not be forgetting the fact that medical students are also in close contact with patients too. Thus, having the true and enough knowledge about the pandemic process and the virus itself is important to their actions because with this way they can overcome the stress. Therefore, they are also at risk for infectious diseases. Even though The American Association of Medical Colleges (AAMC) advised medical schools to not to involve medical students in patient care $(18,19)$, some schools in the US and in Europe graduated their final-year medical students early because of workforce shortage (20) and some volunteer medical student teams were formed (21).

Keeping in mind that today's medical students are the foundation of the future healthcare system, it is important to assess their knowledge on COVID-19 as an example for future pandemics and public health safety issues. In one of the studies about COVID-19 knowledge among the Iranian medical students (5th-7th year), they found that the knowledge of the students is on a high level (21). These results are giving feedback about the worries which is the knowledge and stresses among the future health care workers. Despite the high level of knowledge about COVID-19 among Iranian medical students who participated in the study, self reported preventive behavior does not seem as good. This kind of information about the medical students can let us see country's future health systems. We also want to exa- 
mine Turkish medical students' knowledge during this pandemic period. This study aims to evaluate the knowledge, thoughts and awareness of medical students about the COVID-19 pandemic.

\section{MATERIAL AND METHODS}

This study was approved by the Scientific Research Ethics Committee of Acıbadem University Medical Faculty (Protocol Code: ATADEK 2020-05/40). This descriptive study was carried out between April and May 2020. Individuals other than medical students were not included in the study. The study was conducted via a self-administrative online questionnaire in the Turkish language and delivered through scientific research communities of the medical schools. The participants were informed and their consent for participation was taken at the beginning of the questionnaire.

The questionnaire was prepared via Google For$\mathrm{ms}$ and consisted of 31 questions and five distinct sections. The first section contains the informed consent. The second section consisted of demographic questions: date of birth, gender, current year in university, and the name of the university. The third section was designed to assess the knowledge level of the participants on the COVID-19 pandemic. This section consisted of 14 questions (questions 5th-18th). The fourth and fifth sections were designed to investigate the attitude and behaviors of the students towards/during the pandemic. Section four consisted of 9 questions (questions 19th-27th) and the fifth section consisted of 4 questions (questions 28th-31nd). In the 3rd and 4th sections, checkboxes and multiple-choice questions were utilized; in the 5th section, linear scale questions were used.

Categorical variables are demonstrated as numbers and percentages, whereas continuous variables are presented as the minimum, maximum, and mean values. The IBM SPSS version 23 was used for the presentation of the data.

\section{RESULTS}

A total of 575 participants completed the questionnaire. The mean participant age was $21.7 \pm 1.9$ years (range: $17-33$ years). Three hundred and eighty-three (66.6\%) participants were female, $190(33 \%)$ were male, and $2(0.3 \%)$ did not declare their gender. All participants were undergraduate medical students. The distribution of grades is shown in Table 1. Students from 41 different universities participated in the questionnaire. The highest participation was from Trakya University with a rate of $31.3 \%$.
According to questions, 301 (52.3\%) participants knew about the coronaviridae family before the outbreak, and 223 (38.8\%) were informed about COVID-19 by their universities. Five hundred and seventy-three (99.7\%) students stated that the origin of the pandemic was China. Of the participants, $80 \%$ stated that droplet spread is the transmission route of $\mathrm{CO}$ VID-19 (Table 2). When participants' opinion about the animal to human transmission was asked 310 (53.9\%) students chose "transmittable" for this question, 174 (30.3\%) chose "not transmittable" and 91 (15.8\%) chose "I don't have any idea". In addition, human to pet transmission was not accepted by almost half of the participants [255 (44.3\%)] and 90 (15.7\%) participants didn't have any idea. Being older than 65 years old, having a comorbidity, being immunosuppressed or working in the healthcare sector were the most selected groups with the highest mortality and morbidity risk (Table 3 ). The most common opinion about the incubation period of SARS CoV-2 was 2 - 14 days (Table 4). Dry cough, high fever, and difficulty in breathing or shortness of breath were the main symptoms of SARS CoV-2 according to participants (Table 5). Distributions of answers to symptoms that require the emergency intervention of COVID-19 according to CDC are presented in Table 6. Answers to the epidemiologic history criteria are detailed in Table 7. General opinions about the parameters that are used to investigate COVID-19 diagnosis can be seen in Table 8 . Nasopharyngeal swab (58.96\%) followed by oropharyngeal swab (53.39\%) were the most common answers to the question of which clinical samples can be used in the diagnosis (Table 9). Distribution of answers to the question about the importance of social isolation is detailed is detailed in Table 10.

More than half of the participants follow vaccine developments from social media [341 (59.30\%)], radio and television (45.36\%) (Table 11). Mask, gloves, cologne, and alcohol-based antiseptic solutions were the most common items used by students as a precaution (Table 12). According to $75.83 \%$ of the participants, all people should wear a mask in daily life (Table 13). Almost half of the participants wash their hands with water and soap 5-9 times a day and they spend 10-19 seconds per wash (Table 14-15). During the COVID-19 pandemic period, $56.0 \%$ of participants think that interns can be called for duty in a state of emergency. The most common lack of healthcare professionals working in Turkey during the COVID-19 pandemic was personal protective equipment (57.0\%) according to participants (Table 16). Of the participants, $38.1 \%$ thought that they had a maximum of $20.0 \%$ risk of getting infected (Table 17). The most common answer (28.0\%) to the risk of a family 
member being infected was between $20-40 \%$ (Table 18).

Information pollution related to the pandemic, the social responsibility awareness of the student from the first case in Turkey, the disruption level of medical education was scored in the questionnaire. Whether there was a change in the departments they were planning to choose in specialization was questioned. The average score and standard deviation of the answers described in Table 19.

Table 1: Medical school grades' dispersion of the participants.

\begin{tabular}{ccc} 
Grade & Number & Percentage (\%) \\
\hline Preparatory & 1 & 0.17 \\
$\mathbf{1}$ & 191 & 33.21 \\
$\mathbf{2}$ & 128 & 22.26 \\
$\mathbf{3}$ & 102 & 17.73 \\
$\mathbf{4}$ & 59 & 10.26 \\
$\mathbf{5}$ & 74 & 12.86 \\
$\boldsymbol{6}$ & 20 & 3.47 \\
& 575 & 100 \\
\hline
\end{tabular}

Table 2: Responses for the transmission route of the SARS CoV-2.

Route of Transmission

Droplet Spread

Airborne

Direct Contact

Oral

Faecal-oral

I don't have any idea

Total
Number

460

60

10.4

43

7.5

7

1.2

4

0.7

1 0.2

80

5

\section{.}


Table 3: Responses for the criteria to be in risk group for COVID-19.

\begin{tabular}{|c|c|c|}
\hline Risk Group & Number & Percentage (\%) \\
\hline $65+$ age (year) & 486 & 84.52 \\
\hline Comorbidity & 485 & 84.35 \\
\hline $\begin{array}{c}\text { Immunosuppressed } \\
\text { patients }\end{array}$ & 451 & 78.43 \\
\hline Healthcare workers & 350 & 60.87 \\
\hline 55-64 age (year) & 209 & 36.35 \\
\hline Pregnant women & 202 & 35.13 \\
\hline All of them & 81 & 14.09 \\
\hline 45-54 age (year) & 54 & 9.39 \\
\hline $0-19$ age (year) & 27 & 4.7 \\
\hline Other & 16 & 2.78 \\
\hline 20-44 age (year) & 10 & 1.74 \\
\hline I don't have any idea & 1 & 0.17 \\
\hline Total & 575 & 100 \\
\hline
\end{tabular}

(Participants were able to choose more than one option.) 
Table 4: Responses for the incubation period of SARS CoV-2 (days).

\begin{tabular}{ccc}
\hline Incubation Period & Number & Percentage (\%) \\
$\mathbf{0 - 1}$ & 1 & 0.2 \\
$2-14$ & 520 & 90.4 \\
$\mathbf{1 5 - 2 1}$ & 23 & 4 \\
I don't have any idea & 31 & 5.4 \\
Total & 575 & 100 \\
\hline
\end{tabular}

Table 5: Responses for the main symptoms of COVID-19.

\begin{tabular}{ccc} 
Main Symptoms & Number & Percentage (\%) \\
\hline $\begin{array}{c}\text { Having difficulty in } \\
\text { breathing or shortness }\end{array}$ & 529 & 92 \\
High fever & 521 & 90.61 \\
$\quad$ Dry cough & 499 & 86.78 \\
$\begin{array}{c}\text { Persistent pain or pressure } \\
\text { in the chest }\end{array}$ & 230 & 40 \\
New confusion & 79 & 13.74 \\
Bluish lips or face & 53 & 9.22 \\
All of them & 35 & 6.09 \\
$\quad$ Sputum cough & 31 & 5.39 \\
Other & 16 & 2.78 \\
$\quad$ Total & 575 & 100 \\
\hline
\end{tabular}

(Participants were able to choose more than one option.) 
Table 6: Responses for emergency symptoms of COVID-19.

Emergency Symptoms

Having difficulty in

breathing or shortness

Chronic fever

Persistent pain or pressure

in the chest

New confusion

Bluish lips or face

Dry cough

I don't have any idea

All of them

Sputum cough

Other

Total
Number

494

293

50.96

205

35.65

161

28

155

26.96

86

14.96

44

7.65

13

2.26

10

1.74

4

0.7

575

100

(Participants were able to choose more than one option.) 
Table 7: Responses for epidemiologic history of COVID-19

Epidemiologic History

All of them

Contact with a COVID-19

positive case

Travel to risky areas

Fever or respiratory tract

symptoms and contact with

a case came from a risky

area

Contact with a case came

from a risky area and 2 or

more cases with fever/

respiratory tract symptoms

in the close area (school,

family, work etc.)

I don't have any idea

Other

Total
Number

Percentage (\%)
430

74.78

137

23.83

132

22.96

126

21.91

91

15.83

4

0.7

1

0.17

100

(Participants were able to choose more than one option.) 
Table 8: Responses for the diagnostic parameters of COVID-19.

Diagnostic Parameters

All of them

Clinical findings

Contact with a person with

COVID-19 suspicion

PCR

Radiological examinations like tomography

Blood examinations like complete blood count, CRP

I don't have any idea

Other

Total
Number

268

260

251

43.65

223

38.78

175

30.43

72

13

0.17

575

100

(Participants were able to choose more than one option.) 
Table 9: Responses for the test samples of COVID-19.

\begin{tabular}{|c|c|c|}
\hline Test Samples & Number & Percentage (\%) \\
\hline Nasopharyngeal swab & 339 & 58.96 \\
\hline Oropharyngeal swab & 307 & 53.39 \\
\hline Bronchoalveolar lavage & 187 & 32.52 \\
\hline Phlegm & 143 & 24.87 \\
\hline Tracheal aspiration & 139 & 24.17 \\
\hline $\begin{array}{c}\text { Nasopharyngeal } \\
\text { wash/aspiration or nasal } \\
\text { aspiration }\end{array}$ & 136 & 23.65 \\
\hline I don't have any idea & 119 & 20.7 \\
\hline All of them & 38 & 6.61 \\
\hline Stool & 18 & 3.13 \\
\hline Other & 3 & 0.52 \\
\hline Total & 575 & 100 \\
\hline
\end{tabular}

(Participants were able to choose more than one option.) 
Table 10: Responses for the importance of social isolation.

\begin{tabular}{ccc} 
Social Isolation & Number & Percentage (\%) \\
\hline $\begin{array}{c}\text { All of them } \\
\begin{array}{c}\text { To prevent older people and } \\
\text { people with chronic diseases } \\
\text { from getting infected }\end{array}\end{array}$ & 388 & 67.48 \\
$\begin{array}{c}\text { To prevent healthy people } \\
\text { from getting infected }\end{array}$ & 159 & 27.65 \\
$\begin{array}{c}\text { To decrease the workload of } \\
\text { healthcare centers }\end{array}$ & 128 & 22.26 \\
I don't have any idea & 120 & 20.87 \\
Other & 5 & 0.87 \\
Total & 3 & 0.52 \\
\hline
\end{tabular}

(Participants were able to choose more than one option.)

Table 11: Responses for following vaccine development.

Following Vaccine Development

Social media

Radio and television

Popular science platforms

Scientific studies or meetings
I don't follow

Other

Total
Percentage (\%)
154

100

12

575

341

261

199

34.61

26.78

17.39

2.09

100 
Table 12: Precautions that the students take for themselves or the people around them.

Precautions

Social isolation

Mask

Home ventilation

Cologne

Alcohol based antiseptic solutions

Gloves

All of them

Other

Total
Number

410

369

349

332

218

214

156

1

575
0.17

Percentage (\%)

71.3

64.17

60.7

57.74

37.91

37.22

27.13

100

(Participants were able to choose more than one option.) 
Table 13: The distribution of answers to the question regarding the people who need to wear a mask in daily life.

People Who Need to Wear

a Mask

All people

Sick people

People with suspected

disease

People in contact with sick

people

Healthy people

Other

Total
Number

436

133

131

121

15

5

575
22.78

21.04

2.61

0.87

75.83

100

(Participants were able to choose more than one option.)

Table 14: Daily frequency of hand-washing.

Daily Frequency of Hand-

Washing

$0-4$

5-9

10-14

$15+$

Total
Number

62

269

189

55

575
Percentage (\%)

10.78

46.78

32.86

9.56

100 
Table 15: The average hand-washing times of the participants.

\begin{tabular}{ccc}
$\begin{array}{c}\text { Average Hand-Washing } \\
\text { Time (s) }\end{array}$ & Number & Percentage (\%) \\
\hline $\mathbf{0 - 9}$ & 28 & 4.9 \\
$\mathbf{1 0 - 1 9}$ & 271 & 47.1 \\
$\mathbf{2 0 - 3 9}$ & 255 & 44.3 \\
$\mathbf{4 0 - 5 9}$ & 15 & 2.6 \\
$\mathbf{6 0 +}$ & 6 & 1.0 \\
Total & 575 & 100 \\
\hline
\end{tabular}

Table 16: The greatest lack of healthcare professionals.

Lack

Number

328

Personal protective equipment

Materials to treat patients,

67 such as medication or ventilator

Motivation

No lack

Other

Total
67

72

41

575
Percentage (\%)
11.7

11.7

12.5

7.1

100 
Table 17: Perception of self-risk of being infected in current pandemic period.

\begin{tabular}{ccc} 
Percentage of Risk (\%) & Number & Percentage (\%) \\
\hline $\mathbf{0 - 2 0}$ & 219 & 38.1 \\
\hline $\mathbf{2 1 - 4 0}$ & 169 & 29.4 \\
$\mathbf{4 1 - 6 0}$ & 121 & 7 \\
$\mathbf{6 1 - 8 0}$ & 40 & 21 \\
$\mathbf{8 1 - 1 0 0}$ & 26 & 4.5 \\
Total & 575 & 100
\end{tabular}

Table 18: Perception of the risk of a family member being infected in current pandemic period.

Percentage of Risk (\%)

$$
0-20
$$

$21-40$

41-60

61-80

81-100

Total
Number

219

169

121

40

26

575
4.5

Percentage (\%)

38.1

29.4

21

7

100 
Table 19: The average score and standart deviation of lineer scale questions.

\begin{tabular}{cccc} 
Questions & Minimum-Maximum & Average Score & Standart Deviation \\
\hline $\begin{array}{c}\text { Information accuracy about } \\
\text { the pandemic }\end{array}$ & $1-5$ & 3.98 & 0.96 \\
$\begin{array}{c}\text { The social responsibility } \\
\text { awareness expected to occur } \\
\text { from the first case in Turkey }\end{array}$ & $1-5$ & 3.82 & \\
$\begin{array}{c}\text { Disruption level of medical } \\
\text { education }\end{array}$ & $1-5$ & 4.21 \\
\\
$\begin{array}{c}\text { Change in the department } \\
\text { of the speciality planned }\end{array}$
\end{tabular}

(Rated 1 to 5.)

\section{DISCUSSION}

Since the COVID-19 outbreak in December 2019, there has been a great concern among all the people in the world. The knowledge of and attitudes towards infectious diseases are very important for the health and safety of students (22). As healthcare workers, medical students are at higher risk for infectious diseases as well (23). In the future, in case of an epidemic/pandemic, today's medical students will be the healthcare professionals who are responsible for the care of the general public. Therefore, it is important to determine their knowledge, thoughts, and awareness about the COVID-19 pandemic.

In this study, 575 medical students from different medical schools in Turkey filled out an online survey, and results were evaluated descriptively. In our study, $52.3 \%$ of medical students who participated in this questionnaire had knowledge of coronaviridae family before the COVID-19 pandemic and $38.8 \%$ were informed about the COVID-19 in their faculties. Similarly, Taghrir et al. (21) reported that $43.3 \%$ of medical students received education about COVID-19. These rates show that the majority of medical students have not been trained about COVID-19. Although most medical students may not be trained on this subject,
99.7\% of the students stated that the first case was seen in China. In the study of Taghrir et al. (21), this rate was $91.7 \%$ which was lower than our study. COVID-19 was first detected in China presented as atypical pneumonia in December 2019 (2). It may mean that, in the pandemic period we live in, the vast majority of medical students are informed by their own means. Eighty percent of students stated that the droplet spread is the main transmission route, which was lower than Iranian medical students (21). COVID-19 is a viral infection that can spread through ingestion or inhalation of respiratory droplets (9). Of the students, $53.9 \%$ stated that SARS-CoV-2 can be transmitted from an infected animal to a non-infected person and $40 \%$ stated that it can be transmitted from an infected person to a non-infected pet. SARS-CoV-2 is thought to be primarily transmitted from bats to humans and is transmitted from person to person (24). There are not many studies or case reports indicating that the virus is transmitted from human to animal. However, the first case seen in an animal was the tiger in a zoo in the United States and the test was positive for SARS CoV-2 (25). Until this time, 2 dogs and 2 domestic cats have tested positive for SARS CoV-2. The common feature of these animals is that they live with infected owners (26). 
Identifying the risk groups for COVID-19 is important to manage the outbreak and to take preventive measures. Although there are many guidelines suggesting different risk groups for the disease, they agree on the major ones such as 65+ age (year), comorbidities and immunosuppressed patients (27-29). The National Health Service (NHS) suggests two risk group categories: high risk (clinically extremely vulnerable) and moderate risk (clinically vulnerable) (27). The NHS includes people who are pregnant in the moderate risk group although a study done by Zhang et al. (29) reported the neonates of the infected women did not carry the SARS-CoV-2 infection. The prognosis for pregnant women was indifferent to the general public (29). Despite the different approaches, the medical students who participated in our study have a good level of knowledge according to their answers: $84.52 \%$ for people older than 65 years, $84.35 \%$ people with comorbidities, and $78.43 \%$ for immunosuppressed people being the most common risk groups.

The incubation period of SARS-CoV-2 is 2-14 days (29-31). However, an article published in JAMA reported a case with an incubation period of 19 days (8). $90.4 \%$ of the participants answered the question in accordance with the literature.

The main symptoms of COVID-19 are fever, cough, dyspnea, and headache $(7,32,33)$. The participants showed good knowledge; 92\% for dyspnea, 90.61\% for high fever, and $86.78 \%$ for coughing. Nevertheless, there are many atypical symptoms to the SARS-CoV-2 infection and a certain percentage of the patients are asymptomatic and diagnosed via screening protocols (32-34). According to the study done by Kong et al. (32), asymptomatic patients had similar comorbidity ratios, but they were younger.

Emergency symptoms listed on CDC are trouble in breathing, persistent pain or pressure in the chest, new confusion, inability to wake or stay awake, and bluish lips or face (7). The participants' answers; $85.91 \%$ for dyspnea, $50.96 \%$ for high fever, and $35.65 \%$ for chest pain showed that they were somewhat aware of the emergency symptoms. People who experience any of the emergency symptoms are recommended to seek medical care as soon as possible and the guidance of medical students can play a role in timely referrals (7). Turkish Ministry of Health's guideline states a detailed patient history including travel to risky areas, contact with a COVID-19 positive case, fever or respiratory tract symptoms should be taken from potential COVID-19 patients (35). The Ministry of Health also developed an app called "Hayat Eve Siğar" (HES) (Stay at
Home) which uses mobile phone signals to track possible contact with COVID-19 positive cases and inform the users of high-risk areas (36). The joint effort of the Ministry of Health and the media might be the reason that $74.78 \%$ of the participants answered in accordance with the guidelines.

Molecular assay testing is the accepted method of diagnosis for COVID-19 (36-38). Li et al. (38) showed that chest CT can be helpful as a rapid diagnostic method combined with patient history and clinical examination although the molecular assay is currently the only accepted method for the confirmation of the disease (39). The answers correlate with the literature; 91.83\% said clinical findings, $85.39 \%$ said PCR, and $77.04 \%$ said radiological investigations such as CT scan would be helpful in the diagnosis.

The CDC guideline recommends the specimen to be collected by a healthcare provider from the nasopharynx or oropharynx (40). Participants answered in accordance with the guideline with $58.96 \%$ saying nasopharynx and $53.39 \%$ saying oropharynx. However, a study performed by $\mathrm{Gu}$ et al. (41) showed the virus could be isolated from the stool of a patient even after they are released from the hospital. 3.13\% of the participants said a stool sample could be used in the diagnosis. On April 21st, the FDA authorized the first test with at-home sample collection which also allows the nasopharynx or oropharynx sampling (41).

Various limitations have been forced on society to contain the spread of the infection. Individuals are compelled to remain at home and to isolate socially (42). According to our results, the importance of social isolation is unignorable. $27.65 \%$ of the students think that social isolation is necessary to prevent older people and people with chronic diseases to get infected. While 128 students thought it was important to prevent healthy people from becoming infected, 120 students said it was important to reduce the workload of health institutions. The reason that the number of students who choose these options is very close, maybe due to the linear relationship between the workload of the health system and the infected people.

COVID-19 can be transmitted from infected people without symptoms and its ability to cause a pandemic in a couple of months suggests that control of it will be hard without a vaccine (43). Therefore, we asked medical students if they are following anything about vaccine development. 261 of medical students are following vaccine development via radio and television, while 341 of them are following only via social media. There are 100 students who do not follow any development. 
This shows us that social media is an important way to be up to date among medical students.

Ağalar et al. (44) stated that patients should wear masks during the whole time they are at the hospital and there should be hand sanitizers at the hospital entrance, waiting rooms, etc. Considering the importance of precautions such as wearing masks and gloves, using alcohol-based antiseptic solutions and cologne, home ventilation, social isolation, 156 of the students stated that they had all of the precautions listed on the questionnaire. 410 students only isolated themselves. Because its easy to implement, social isolation is the most preferred precaution.

Four hundred thirty-six medical students think that all people should wear masks. Wearing medical masks could reduce infection risk by $30 \%$ (45). This indicates that most of the medical students are aware of the benefit of wearing a mask. 269 students out of 575 reported that they are washing their hands 5 to 9 times in a day. It takes $10-19$ seconds to wash hands for $47.1 \%$ of the students, also for $44.3 \%$ of the students, washing hands takes 20-39 seconds. An average recomended time to wash hands is 20 seconds (46). Compared to our study, it can be said that most medical students know how long they should wash their hands. In addition, $56 \%$ of students think that only intern doctors should be called back to school in case of an emergency. It is thought that intern doctors are competent among medical students.

According to $57 \%$ of participants, the greatest lack of healthcare professionals working in Turkey during the COVID-19 pandemic period is personal protective equipments such as masks, gloves, and safety goggles. Given that all protective equipment come via a chain of events, it is a known fact that the COVID-19 pandemic has disrupted the healthcare supply chain

worldwide with shortages of raw materials and dramatic increases in prices (47). $11.7 \%$ of participants were worried if healthcare professionals had enough materials such as medication or ventilators necessary for the treatment of COVID-19 patients. Only $12.5 \%$ of participants thought that healthcare professionals lacked nothing, but this number is the minority. Interestingly, the participants were not as concerned about getting infected as they were of healthcare equipment. $38.1 \%$ of participants think the risk of themselves being infected is only $0-20 \%$. Only $4.5 \%$ of the patients thought their risk of being infected was $81-100 \%$, but this ratio increased to $8 \%$ when they were asked about the risk of a family member being infected. This data suggests that the students are more concerned about their family mem- bers' health. This might be due to the fact that family members go to work and the work environment could be risky. Besides, the students might be concerned if their family members are as careful as them by taking the necessary precautions against the virus. A reason for this might be that college students, who are very exposed to social media were cognizant of all aspects of the COVID-19 pandemic, and therefore the majority had many concerns (48). All the participants of our survey were medical students, therefore different results might have been obtained from students studying another major. There is a significant data that health education specifically aimed at improving knowledge of COVID-19 can help them maintain an optimistic attitude (49). Since our participants might have known about COVID-19 more than an average person, their concern levels might have been different. On a scale of 1 to 5 , the participants rated their thoughts on information pollution during the pandemic as an average of 3.98. Bastani et al. (49) suggests that increased demand for information during the crisis, the easiness of information dissemination via social networks, marketing incentives, and the poor legal supervision of online content are the main reasons for misinformation dissemination. The study explains "disease statistics, treatments, vaccines and medicines; prevention and protection methods; dietary recommendations and disease transmission ways are the main subjective categories of releasing misinformation in regard to novel coronavirus outbreak" (49). It is important to remember that misinformation dissemination regarding disease causes psychosocial consequences; anxiety and depression during the pandemic lead to somatic symptoms that in turn cause significant physical and mental discomfort (48).

Although many think that they received incorrect information sometimes, they rated their social responsibility awareness from the first case in Turkey an average of 3.82. The participants, who are all medical school students, scored their disruption level of medical education during the pandemic as 4.64. As Ferrel et al. (50) explains, the irreplaceable value of attending class in-person was hard to replicate in online forums, especially for medical students. When the participants were asked whether there was a change in the departments they were planning to choose in specialization, the rate was 2.43. This indicated that the majority of students did not have any particular interest change during the pandemic. 
In our study, there were some significant limitations. One of them was that the questionnaire we conducted to students is online. With the online questionnaire, some marking problems have occurred. One of our other limitations was to deliver the survey to students. Therefore, further studies with more participants are needed in this regard.

In conclusion, the epidemiology and diagnostic factors of COVID-19 are mostly well known by the medical students. To minimize information pollution and raise awareness, medical students should be educated about pandemic and management of it. Further experiments with various methods and more participants are needed to better understand the awareness of the COVID-19 pandemic.

Ethics Committee Approval: This retrospective study was approved by the Scientific Research Ethics Committee of Acıbadem University School of Medicine

Informed Consent: Online informed consent was obtained from the participants of this study.

Conflict of Interest: The authors declared no conflict of interest.

Author contributions: Concept: HSÇ, AE, BK, BG, SK, BK, HOİ, NK, EŞ, EA, BT, AG, ATC, AUM, BB, EC, NKÇ, CE, MZD, SA, MŞ, SGG. Supervision: HSÇ, AE, BK, BG, SK, BK, HOİ, NK, EŞ, EA, BT, AG, ATC, AUM, BB, EC, NKÇ, CE, MZD, SA, MŞ, SGG. Resources: HSÇ, AE, BK, BG, SK, BK, HOİ, NK, EŞ, EA, BT, AG, ATC, AUM, BB, EC, NKÇ, CE, MZD, SA, MŞ, SGG. Materials: HSÇ, AE, BK, BG, SK, BK, HOİ, NK, EŞ, EA, BT, AG, ATC, AUM, BB, EC, NKÇ, CE, MZD, SA, MŞ, SGG. Data collection and/or processing: HSÇ, AE, BK, BG, SK, BK, HOİ, NK, EŞ, EA, BT, AG, ATC, AUM, BB, EC, NKÇ, CE, MZD, SA, MŞ, SGG. Analysis and/or Interpretation: HSÇ, AE, BK, BG, SK, BK, HOİ, NK, EŞ, EA, BT, AG, ATC, AUM, BB, EC, NKÇ, CE, MZD, SA, MŞ, SGG. Literature Search: HSÇ, AE, BK, BG, SK, BK, HOİ, NK, EŞ, EA, BT, AG, ATC, AUM, BB, EC, NKÇ, CE, MZD, SA, MŞ, SGG. Writing Manuscript: HSÇ, AE, BK, BG, SK, BK, HOİ, NK, EŞ, EA, BT, AG, ATC, AUM, BB, EC, NKÇ, CE, MZD, SA, MŞ, SGG. Critical Review: HSÇ, AE, BK, BG, SK, BK, HOİ, NK, EŞ, EA, BT, AG, ATC, AUM, BB, EC, NKÇ, CE, MZD, SA, MŞ, SGG.

Financial disclosure: The authors declared that this study received no financial support.

Editor-in-chief's Note: Sixteen authors of this article, Hilal Sena Çifcibaşı, Alperen Elibol, Berkay Kef, Bengisu Gür, Selin Kolsuz, Berra Kurtoğlu, Hasan Orkun İpsalalı, Nazlıcan Kükürtcü, Ece Şenyiğit, Ekin Altınbaş, Berfin Tan, Aslı Göztepe, Alperen Taha Certel, Arda Ulaş Mutlu, Burak Bardakçı, Elif Cengiz are members of the editorial board of Turkish Medical Student Journal. However, they did not take place in any stage on the editorial decision of the manuscript. The editors who evaluated this manuscript are from other institutions.

Acknowledgments: We would like to express our gratitude to Müberra Devrim Güner for her contributions to our article.

\section{REFERENCES}

1. Zhou P, Yang XL, Wang XG et al. A pneumonia outbreak associated with a new coronavirus of probable bat origin. Nature 2020;579(7798):270-3.

2. Report of clustering pneumonia of unknown etiology in $\mathrm{Wu}-$ han City. Wuhan Municipal Health Commission. (cited 2020 May 25). Available from: URL: https://www.who.int/csr/don/05-january-2020-pneumonia-of-unkown-cause-china/en/.

3. Lai CC, Shih TP, Koc WC et al. Severe acute respiratory syndrome coronavirus 2 (SARS-CoV-2) and coronavirus disease-2019 (COVID-19): the epidemic and the challenges. Int J Antimicrob Agents 2020;55(3)105924.

4. Guan WJ, Liang WH, Zhao Y et al. Comorbidity and its impact on 1590 patients with COVID-19 in China: a nationwide analysis. Eur Respir J 2020;55(5):2000547.

5. Xia S, Zhu Y, Liu M et al. Fusion mechanism of 2019-nCoV and fusion inhibitors targeting HR1 domain in spike protein. Cell Moll Immunol 2020 February 11 (cited 2020 May 6). Available from: URL: https://www.nature.com/articles/s41423-020-0374-2.

6. Yi Y, Lagniton PNP, Ye S et al. COVID-19: what has been learned and to be learned about the novel coronavirus disease. Int J Biol Sci 2020;16(10):1753-66.

7. Symptoms of Coronavirus. Centers for Disease Control and Prevention 2020 May 13. Available from: URL:www.cdc.gov/coronavirus/2019-ncov/symptoms-testing/symptoms.html.

8. Bai Y, Yao L, Wei T et al. Presumed asymptomatic carrier transmission of COVID-19. Jama 2020;323(14):1406.

9. Boopathi S, Poma AB, Kolandaivel P. Novel 2019 coronavirus structure, mechanism of action, antiviral drug promises and rule out against its treatment. J Biomol Struct Dyn 2020 Apr 20. doi: 10.1080/07391102.2020.1758788. [Epub ahead of print].

10. Li X, Geng M, Peng Y et al. Molecular immune pathogenesis and diagnosis of COVID-19. J Pharm Biomed Anal 2020;10(2):102-8.

11. Petruzzi G, Virgilio AD, Pichi B et al. COVID-19: nasal and oropharyngeal swab. Head \& Neck 2020;42(6):1303-4. doi:10.1002/ hed.26212. [Epub ahead of print].

12. Clinical Specimens: Novel Coronavirus (2019-nCoV). Centers for Disease Control and Prevention 2020 May. Available from: URL:https://www.cdc.gov/coronavirus/2019-ncov/lab/guidelines-clinical-specimens.html.

13. Li Y, Xia L. Coronavirus disease 2019 (COVID-19): role of chest CT in diagnosis and management. AJR Am J Roentgenol 2020 Mar;4:1-7. doi: 10.2214/AJR.20.22954 [Epub ahead of print].

14. Wu W, Xu Z, Jin Y et al. Key points of clinical and CT imaging features of 2019 novel coronavirus (2019-nCoV) imported pneumonia based on 21 cases analysis. 2020 Jun. doi: https://doi.org/10.1101/202 0.03.03.20030775. [Epub ahead of print].

15. Cui J, Li F, Shi Z. Origin and evolution of pathogenic coronaviruses. Nat Rev Microbiol 2019;17(3):181-92.

16. Lai CC, Shih TP, Ko WC et al. Severe acute respiratory syndrome coronavirus 2 (SARS-CoV-2) and corona virus disease-2019 (COVID-19): the epidemic and the challenges. Int J Antimicrob Agents 2020;55(3):1-29. 
17. Chang D, Xu H, Rebaza A et al. Protecting health-care workers from subclinical coronavirus infection. Lancet Respir Med 2020;8(3):1-13.

18. Whelan A, Prescott J, Young G et al. Guidance on medical students' clinical participation: effective immediately. Acad Med 2020 Apr 14;1:1-6.

19. Whelan A, Prescott J, Young G et al. Interim guidance on medical students' participation in direct patient contact activities: principles and guidelines. Acad Med 2020 March 30;1:1-3.

20. Amante A, Balmer C. Italy rushes new doctors into service as coronavirus deaths rise above 2,500. Reuters 2020 (cited 2020 May 6). Available from: URL: https://www.reuters.com/article/us-health-coronavirus-italy-idUSKBN214245.

21. Taghrir MH, Borazjani R, Shiraly R. COVID-19 and Iranian medical students; a survey on their related-knowledge, preventive behaviors and risk perception. Arch Iran Med 2020;23(4):249-54.

22. Soled D, Goel S, Barry D et al. Medical student mobilization during a crisis: lessons from a COVID-19 medical student response team. Acad Med 2020;10. doi: 10.1097/ACM.0000000000003401. [Epud ahead of print].

23. Wang $M$, Han $X$, Fang $H$ et al. Impact of health education on knowledge and behaviors toward infectious diseases among students in Gansu province, China. Biomed Res Int 2018.

24. Xu J, Zhao S, Teng T et al. Systematic comparison of two animal-to-human transmitted human coronaviruses: SARS-CoV-2 and SARS-CoV. Viruses 2020;12(2):244.

25. COVID-19 and animals. Centers for Disease Control and Prevention. Available from: URL:https://www.cdc.gov/coronavirus/2019-ncov/daily-life-coping/animals.html.

26. Leroy EM, Gouilh MA, Brugère-Picoux J. The risk of SARSCoV-2 transmission to pets and other wild and domestic animals strongly mandates a one-health strategy to control the COVID-19 pandemic. One Health 2020;100133.

27. Who's at higher risk from coronavirus. National Health Service. Available from: URL: https://www.nhs.uk/conditions/coronavirus-covid-19/people-at-higher-risk/whos-at-higher-risk-from-coronavirus/.

28. Groups at higher risk for severe illness. Centers for Disease Control and Prevention. Available from: URL: https://www.cdc.gov/coronavirus/2019-ncov/need-extra-precautions/groups-at-higher-risk. html.

29. Zhang L, Jiang Y, Wei M et al. Analysis of the pregnancy outcomes in pregnant women with COVID-19 in Hubei province. Chinese Journal of Obstetrics and Gynecology 2020;55(3):166-71.

30. Jiang X, Rayner S, Luo MH. Does SARS-CoV-2 has a longer incubation period than SARS and MERS?. J Med Virol 2020;92:476-8. 31. Xu XW, Wu XX, Jiang XG et al. Clinical findings in a group of patients infected with the 2019 novel coronavirus (SARS-Cov-2) outside of Wuhan, China: retrospective case series. BMJ 2020;368:m606. 32. Pascarella G, Strumia A, Piliego C et al. COVID-19 diagnosis and management: a comprehensive review. J Intern Med 2020;10.
33. Li L, Huang T, Wang Y et al. COVID-19 patients' clinical characteristics, discharge rate, and fatality rate of meta-analysis. J Med Virol 2020;92:577-83.

34. Kong W, Wang Y, Hu J et al. Comparison of clinical and epidemiological characteristics of asymptomatic and symptomatic SARSCoV-2 infection: a multi-center study in Sichuan province, China. Travel Med Infect Dis 2020.

35. T.C. Sağlık Bakanlığı. COVID-19 (SARS-CoV-2 enfeksiyonu) (bilim kurulu çalışması) genel bilgiler, epidemioloji ve tanı. (serial online) (cited 2020 June 1). Available from: URL: https://covid19bilgi.saglik.gov.tr/depo/rehberler/covid-19-rehberi/COVID-19_REHBERI_GENEL_BILGILER_EPIDEMIYOLOJI_VE_TANI.pdf.

36. T.C. Sağlık Bakanlığı. (serial online) 2020 May (cited 2020 June 1).

Available from: URL: https://www.saglik.gov.tr/TR,65622/koronaviruse-karsi-mucadelemiz-yakin-donemlerdeki-en-buyuk-seferberligimizdir.html.

37. Ahn DG, Shin HJ, Kim MH et al. Current status of epidemiology, diagnosis, therapeutics, and vaccines for novel coronavirus disease 2019 (COVID-19). J Microbiol Biotechnol 2020;30(3):313-24.

38. Li Y, Xia L. Coronavirus disease 2019 (COVID-19): role of chest CT in diagnosis and management. AJR Am J Roentgenol 2020;214:1280-6.

39. WHO. Coronavirus disease (COVID-19) technical guidance: Laboratory testing for 2019-nCoV in humans. Available from: URL: https://www.who.int/emergencies/diseases/novel-coronavirus-2019/ technical-guidance/laboratory-guidance.

40. Interim guidelines for collecting, handling, and testing clinical specimens for COVID-19. Centers for Disease Control and Prevention. Available from: URL: https://www.cdc.gov/coronavirus/2019-ncov/lab/guidelines-clinical-specimens.html.

41. Gu J, Han B, Wang J. COVID-19: gastrointestinal manifestations and potential fecal-oral transmission. Gastro J 2020;158(6):1518-9.

42. Banerjee D, Rai M. Social isolation in Covid-19: the impact of loneliness. International Journal of Social Psychiatry 2020. Available from: URL:https://journals.sagepub.com/doi/ epub/10.1177/0020764020922269.

43. Chen WH, Strych U, Hotez PJ et al. The SARS-CoV-2 vaccine pipeline: an overview. Curr Trop Med Rep 2020;1-4.

44. Agalar C, Ozturk Engin D. Protective measures for COVID-19 for healthcare providers and laboratory personnel. Turk J Med Sci 2020;50(3):578-84.

45. Ma QX, Shan H, Zhang HL et al. Potential utilities of mask-wearing and instant hand hygiene for fighting SARS-CoV-2. J Med Virol. 2020;10.

46. Strohbehn C, Sneed J, Paez P et al. Hand washing frequencies and procedures used in retail food services. J Food Prot 2008;71(8):1641-50.

47. Khot UN. Navigating healthcare supply shortages during the COVID-19 pandemic: a cardiologist's perspective. Circ Cardiovasc Qual Outcomes 2020;13(6):e006801. 
48. Liu S, Liu Y, Liu Y. Somatic symptoms and concern regarding COVID-19 among Chinese college and primary school students: a cross-sectional survey. Psychiatry Res 2020 May 15;289:113070.

49. Bastani P, Bahrami MA. COVID-19 related misinformation on social media: a qualitative study from Iran. J Med Internet Res 5 April 2020 .

50. Ferrel MN, Ryan JJ. The impact of COVID-19 on medical education. Cureus 31 March 2020; 12(3). 